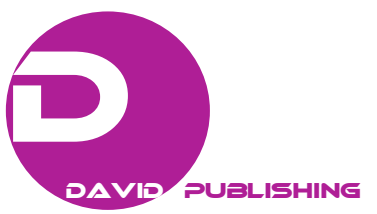

\title{
Finite Element Analysis for Temperature Compensation of ITO Conductive Film System
}

\author{
Wen-Chang Tsao, Wen-Ning Chuang and Min-Wei Hung \\ National Applied Research Laboratories, Taiwan Instrument Research Institute, 20 R\&D Road VI, Hsinchu Science Park, Hsinchu
}

300092, Taiwan

\begin{abstract}
Indium tin oxide (ITO) heating film is primarily used as the defogging component of an instrument observation window. Conventionally, a constant current is used to heat the film. Through the feedback of the temperature sensing component, the output current is adjusted to achieve a set temperature. However, the temperature of the heating film is nonuniformly distributed, and determining the correct output current is time-consuming. This study adopted finite element heat transfer analysis to determine a heating method (such as heat power and heat flux) for an ITO conductive heating film system. The results of the analysis may serve as a reference for temperature compensation in ITO conductive heating films.
\end{abstract}

Key words: ITO film heater, heat transfer analysis, heat power, heat flux.

\section{Introduction}

Condensation may accumulate on the system observation windows of biomedical instrument testing systems because of temperature differences in and outside the system. Consequently, timed video recorders may be obscured by condensation and cannot take clear images. Chuang [1] used a thermal imager to observe the temperature increase process of heating film being heated to determine the power per unit area, system ambient temperature, and heat dissipation conditions of the heating film. The results serve as reference for determining appropriate locations for installing temperature-sensing components on the basis of temperature balance and distribution of heating films. Because Chuang's experiment was easily affected by environmental factors and because preparing for the experiment was time-consuming, the experiment was costly. Therefore, this study adopted finite element heat transfer analysis to determine a heating method (such as heat power and heat flux) for an indium tin oxide (ITO) conductive heating film.

Corresponding author: Wen-Chang Tsao, Ph.D., assistant researcher, research fields: finite element analysis (FEA), mechanical design, digital signal processing (DSP), mechanical fault diagnosis.
The results were compared with those of the temperature balance identified in heating film experiments. Finally, an appropriate temperature compensation value for the temperature sensing element was established.

\section{ITO Conductive Film}

ITO is a mixed oxide of $90 \% \mathrm{In}_{2} \mathrm{O}_{3}$ and $10 \% \mathrm{SnO}_{2}$. The most commonly used material has a composition of ca. $\mathrm{In}_{4} \mathrm{Sn}$. ITO thin film is a highly degenerate n-type semiconductor which has a low electrical resistivity of $2 \sim 4 \times 10^{-4} \Omega \cdot \mathrm{cm}$. The low resistivity value of ITO films has relatively high electrical conductivity [2].

Conductive films with a high visible light transmittance are called transparent conductive films. The characteristics of these films are a transmittance of $60 \%$ or higher and a surface resistance of $10^{10}$ $\Omega \cdot \mathrm{cm}$ or lower [3]. Depending on the material, transparent conductive films consist of metal film, semiconductor oxide film $[4,5]$, nano line [6, 7], and graphene [8]. Among conductive films, the most widely applied are those made through ITO sputtering on PET film base material (ITO films) [9]. ITO films 


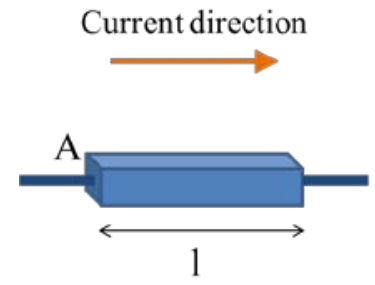

Fig. 1 Calculating resistance [1].

have a transmittance of $80 \%$ or higher in the visible light range. They are applied in products such as windshields, optical lenses, and automotive electronics for heating and defogging. The followings introduce the characteristics of ITO films.

\subsection{Resistance Characteristics of Conductive Film}

Fig. 1 depicts a heating material component. Its resistance $R$ is proportional to resistivity $\rho$ and length $l$ and is inversely proportional to cross-sectional area $A$, as presented in Eq. (1):

Resistance

$$
R=\rho \frac{l}{A}
$$

$A=w \times t$, where $w$ is width and $t$ is thickness.

$$
\text { resistance } R=\rho \frac{l}{A}=\rho \frac{l}{t w}
$$

When a material has uniform thickness, Eq. (2) can be rewritten as follows:

$$
\text { resistance } R=\rho \frac{l}{t w}=R_{s} \frac{l}{w}
$$

where $R_{s}$ is surface resistivity, whose unit is $\Omega / \mathrm{m}^{2}$. Length $l$ is the distance between the positive and negative electrodes of the ITO heating film, and width $w$ is the length of the electrode of the ITO heating film.

The $R_{s}$ of ITO film is primarily related to the sputtering process and material thickness. The $R_{s}$ of ITO films from the same processing batch are a constant. In addition, ITO heating films made with materials of the same specifications have a resistivity that is directly proportional to the length-width ratio of a cut ITO film.

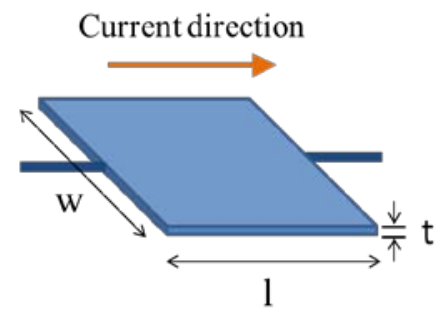

\subsection{Temperature Increase Characteristics of Conductive Film}

To increase the temperature of ITO heating film, a fixed electric power source is supplied to the film. After a period of time, the temperature of the heated film reaches equilibrium. The temperature equilibrium of an ITO film heater is affected by the unit area power of the film, the ambient temperature of the system, and the heat dissipation conditions. A higher unit area power of the heating film leads to higher temperature equilibrium of the system. Likewise, a high system ambient temperature or poor heat dissipation conditions results in higher the temperature equilibrium.

$$
\text { unit area power }=\frac{\text { electric power }}{\text { area of the ITO conductive film }}
$$

\section{Finite Element Analysis}

This study adopted the finite element analysis software Solid Works Simulation to conduct ITO film structure heat transmission analysis. The following sections introduce the design of the ITO film finite element analysis.

\subsection{Conductive Film Model}

The structural geometric model of the ITO conductive film comprises two components, namely (a) ITO film unit and (b) the ITO film system (glass on top of ITO film; Fig. 2). Material characteristics and thermal parameters are listed in Table 1.

\subsection{Condition Settings for Thermal Conduction Simulation of Conductive Film}

When simulating the heating methods for the ITO 
conductive heating film system, the heat source input was divided into heat power (W) and heat flux $\left(\mathrm{W} / \mathrm{cm}^{2}\right)$ on the bottom of the ITO conductive film. The ITO conductive film was cooled to room temperature. The natural convection coefficient of the remaining surfaces to the air was set to 5-25 $\mathrm{W} /\left(\mathrm{m}^{2} \times \mathrm{K}\right)$. The temperature of the testing environment was set to $27^{\circ} \mathrm{C}$ (Fig. 3).

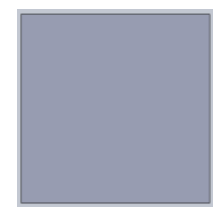

(a) ITO filmunit

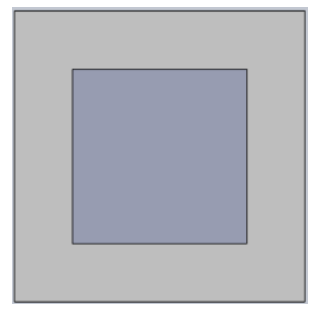

(b) ITO film system
Fig. 2 Geometric model of ITO film components.

Table 1 ITO film and glass material parameters.

\begin{tabular}{|c|c|c|}
\hline Material & PET & Glass \\
\hline Density $\left(\mathrm{kg} / \mathrm{m}^{3}\right)$ & 1,420 & 2,458 \\
\hline Thermal conductivity $(\mathrm{W} / \mathrm{m} \cdot \mathrm{K})$ & 0.261 & 0.749 \\
\hline Specific heat $(\mathrm{J} / \mathrm{kg} \cdot \mathrm{K})$ & 1,140 & 834.6 \\
\hline Specifications(L/W/H, mm) & $120 \times 120 \times 0.4$ & $160 \times 160 \times 2.0$ \\
\hline
\end{tabular}

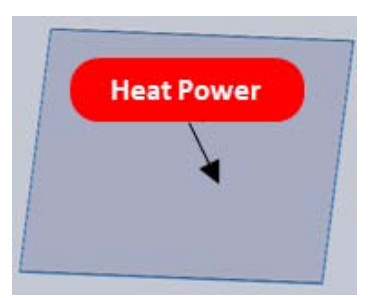

(a) Heat source input

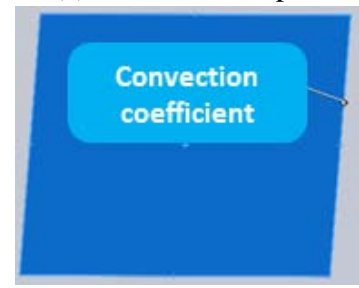

(b) Natural convection coefficient

Fig. 3 Settings for the thermal conduction simulation.

\section{Results and Discussion}

Analysis of the thermal conduction of the ITO film was conducted by examining the methods for setting the heat flux and heat power of the single ITO film and the ITO film system.

\subsection{ITO Thin Film Temperature Measurement Results}

Chuang [1] used fixed current as the power source for an ITO heating film system $(l=120 \mathrm{~mm}, w=120$ $\mathrm{mm})$. The resistivity of the current system was 41.35 $\Omega$, and the working current was $0.5 \mathrm{~A}$. Therefore, the electric power was $10.34 \mathrm{~W}$. A fixed current was provided by the heating system as the power source, and the temperature of the heating film increased from room temperature until reaching an equilibrium. During the heating process, an FLIR C3 thermal imager was used to record the temperature of the heating film. In the experiment, the heating film temperature was sampled at 49 points. The samples were numbered, as presented in Fig. 4. Temperature data $5 \mathrm{~mm}$ from the edge were used for comparison during finite element analysis. Tables 2 and 3 indicate that the temperature measurement scope of the single ITO film and the ITO film system were $55-56{ }^{\circ} \mathrm{C}$ and $49-50{ }^{\circ} \mathrm{C}$, respectively.

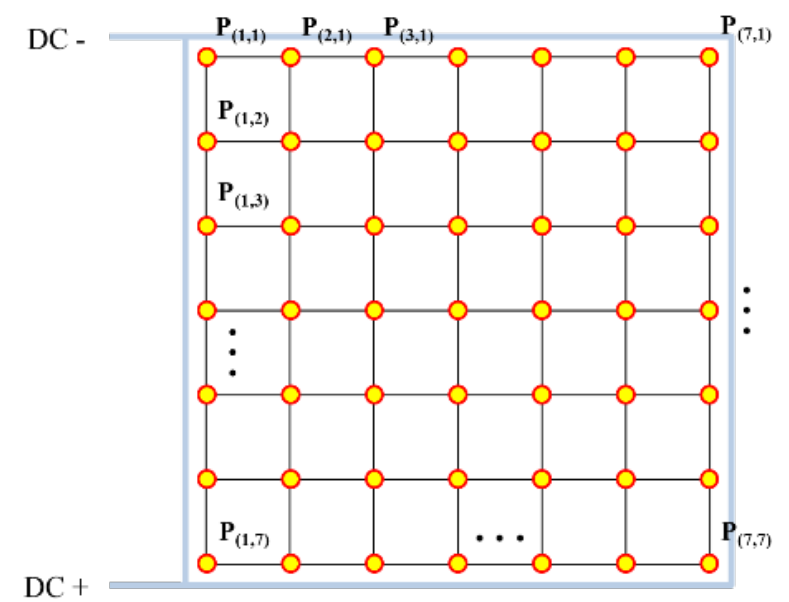

Fig. 4 Location distribution of temperature sampling points.

Table 2 ITO film temperature measurement results [1].

\begin{tabular}{|l|c|c|c|c|c|c|c|}
\hline \multicolumn{7}{|c|}{0.5 A } \\
\hline & MAX & MIN & MAX - MN & \multicolumn{3}{|c|}{ AVG_insid_AVG_all } & \\
\hline & 58.9 & 47.3 & 11.5 & & 57.1 & 55.4 & \\
\hline & A1 & A2 & A3 & A4 & A5 & A6 & A7 \\
\hline B1 & 47.3 & 49.7 & 51.1 & 51.9 & 51.8 & 51.7 & 50.4 \\
\hline B2 & 51.5 & 54.7 & 55.6 & 56.9 & 57.8 & 58.2 & 55.8 \\
\hline B3 & 51.8 & 55.0 & 55.7 & 57.2 & 58.2 & 58.9 & 56.3 \\
\hline B4 & 52.2 & 55.5 & 56.3 & 57.4 & 58.3 & 58.1 & 55.9 \\
\hline B5 & 53.3 & 56.5 & 57.0 & 57.1 & 58.0 & 58.0 & 55.3 \\
\hline B6 & 53.8 & 57.5 & 57.8 & 57.4 & 57.6 & 57.8 & 55.1 \\
\hline B7 & 52.6 & 56.7 & 57.0 & 56.8 & 57.3 & 57.6 & 54.6 \\
\hline
\end{tabular}


Table 3 ITO film system temperature measurement results [1].

\begin{tabular}{|c|c|c|c|c|c|c|c|}
\hline \multicolumn{8}{|c|}{$0.5 \mathrm{~A}$} \\
\hline & MAX & MIN & MAX - MIN & & AVG_insid & AVG_all & \\
\hline & 55.88354 & $\begin{array}{r}49.76657 \\
\end{array}$ & 16.1 & & 53.17231 & 50.33578 & \\
\hline & $\mathrm{Al}$ & $\mathrm{A} 2$ & $\mathrm{~A} 3$ & A4 & A5 & A6 & A7 \\
\hline B1 & 39.8 & 44.3 & 45.6 & 46.8 & 47.5 & 47.4 & 44.0 \\
\hline B2 & 44.1 & 49.6 & 51.5 & 53.1 & 53.9 & 53.6 & 49.2 \\
\hline B3 & 45.1 & 50.3 & 52.2 & 54.6 & 55.7 & 55.9 & 50.5 \\
\hline B4 & 45.5 & 50.2 & 51.8 & 54.1 & 55.2 & 55.2 & 50.7 \\
\hline B5 & 46.1 & 50.9 & 52.1 & 53.4 & 54.4 & 54.4 & 50.5 \\
\hline B6 & 46.6 & 52.0 & 53.1 & 53.5 & 54.0 & 54.4 & 50.4 \\
\hline B7 & 43.6 & 48.8 & 50.2 & 50.5 & 51.0 & 51.5 & 47.5 \\
\hline
\end{tabular}

\subsection{Heat Power Analysis Results}

Fig. 5 presents the results of the heat power analysis of the ITO film with a heat power of $10 \mathrm{~W}$ and a natural convection coefficient of $6 \mathrm{~W} /\left(\mathrm{m}^{2} \times \mathrm{K}\right)$. Fig. $5 \mathrm{a}$ indicates that the temperatures at the center and edge of the single ITO film were $165{ }^{\circ} \mathrm{C}$ and $597{ }^{\circ} \mathrm{C}$, respectively. The temperature distribution was inconsistent with the actual measured temperatures. In the ITO film system, the temperatures at the center and edge of the glass were $75{ }^{\circ} \mathrm{C}$ and $72{ }^{\circ} \mathrm{C}$, respectively, which were also inconsistent with the actual measured temperatures (Fig. 5b). With this heat flux setting method, excessive thermal energy was input in the ITO film, resulting in an excessively high temperature and an unreasonable distribution. Subsequently, heat flux was used to analyze the ITO film thermal input.

\subsection{Heat Flux Analysis Results}

For ITO film thermal input, a heat flux of 345 $\mathrm{W} / \mathrm{m}^{2}$ and a natural convection coefficient of 6 $\mathrm{W} /\left(\mathrm{m}^{2} \times \mathrm{K}\right)$ was selected, the results of which are presented in Fig. 6. Fig. 6a indicates that the temperatures observed at the single ITO film observation points were between 55 and $56{ }^{\circ} \mathrm{C}$, which was consistent with the experimental temperature. The surface temperatures at the center and edge of the ITO film were $59{ }^{\circ} \mathrm{C}$ and $42{ }^{\circ} \mathrm{C}$, respectively. In addition, the temperatures at the ITO film system observation points were $49{ }^{\circ} \mathrm{C}$, which was the same as the temperature measured during the experiment. The temperature of the glass center was approximately $56^{\circ} \mathrm{C}$, whereas the temperature at the edge decreased to $28-29{ }^{\circ} \mathrm{C}$ (Fig. $6 b)$. Therefore, using heat flux as the ITO film thermal input could produce a more reasonable temperature distribution result, which may serve as reference for future temperature compensation experiments.

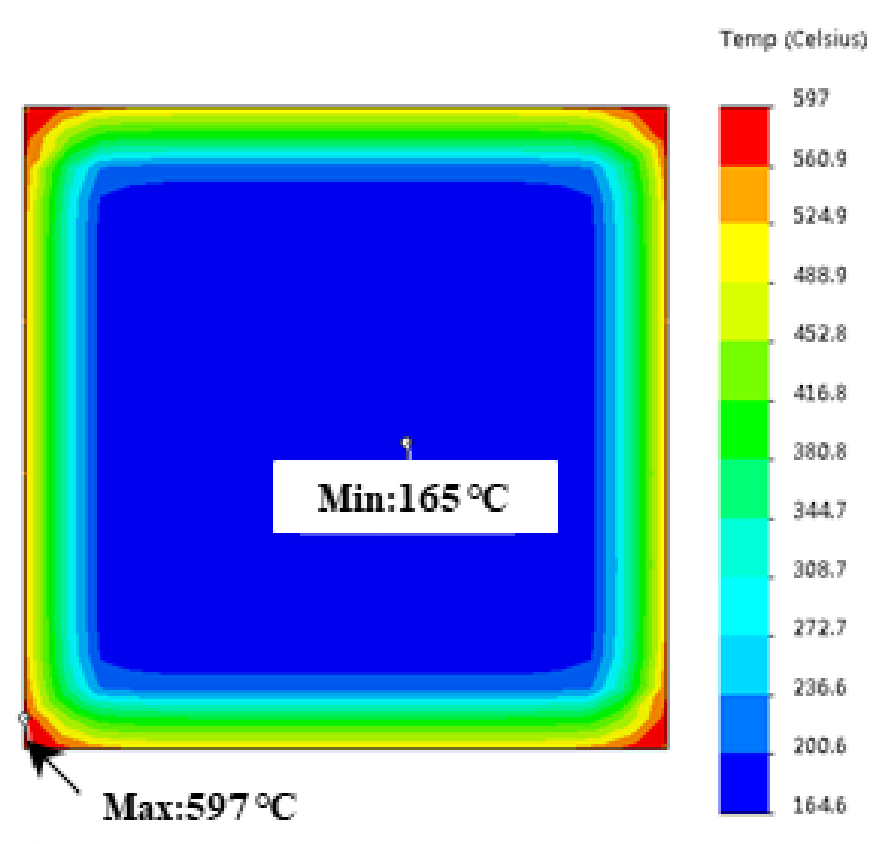

(a) ITO film 


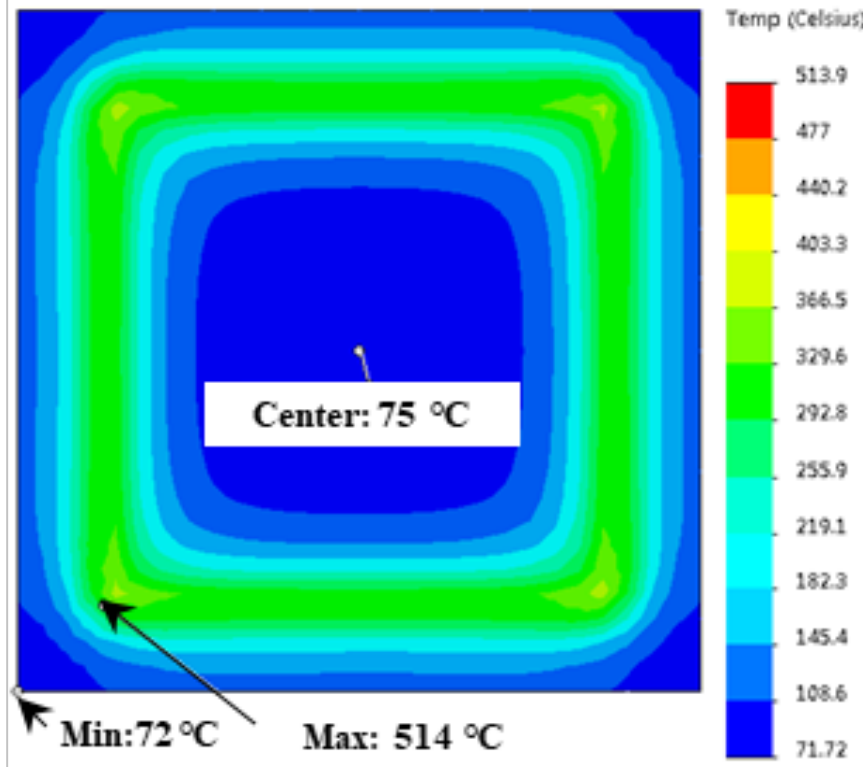

(b) ITO film system

Fig. 5 Heat power analysis results.

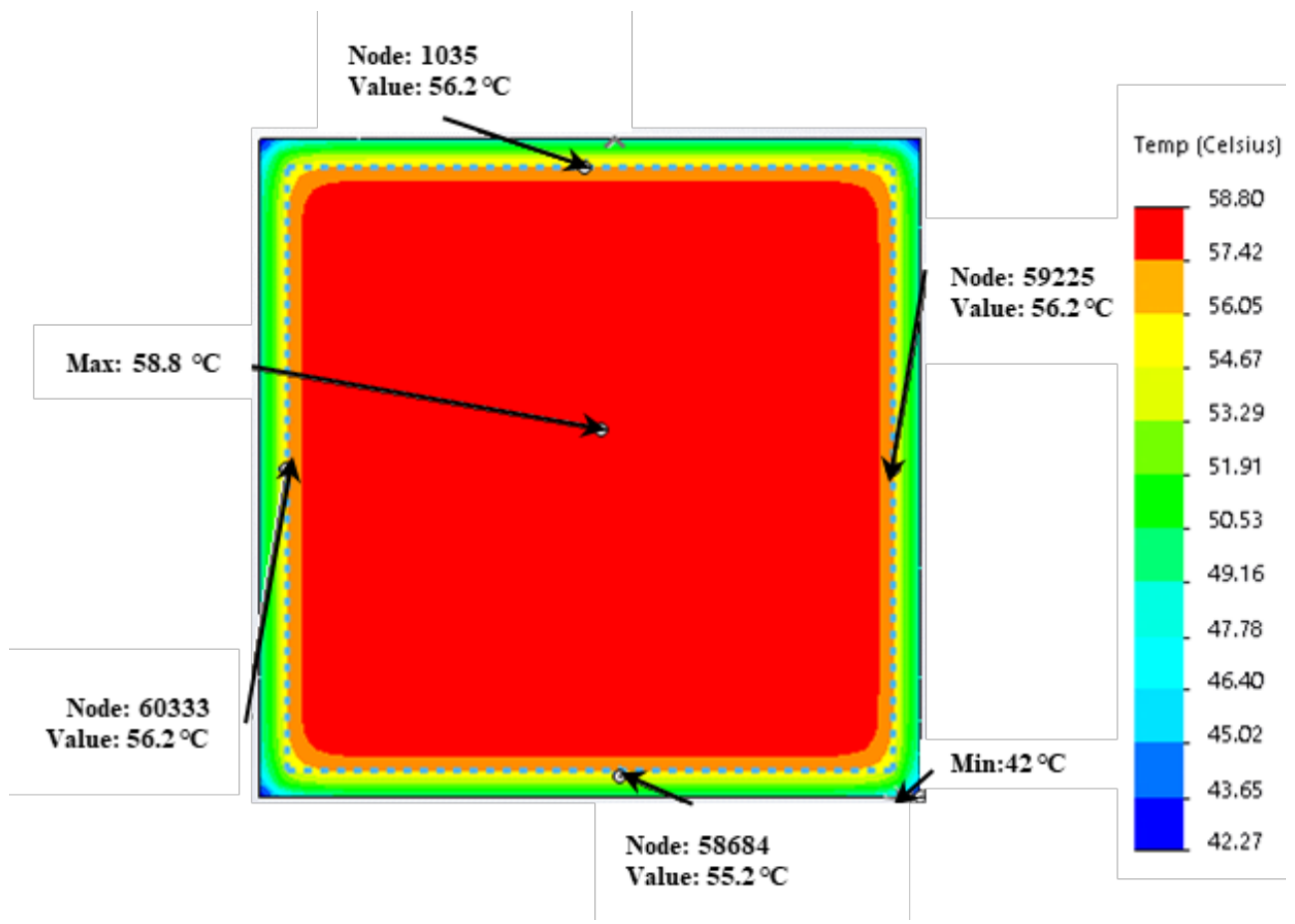

(a) ITO film 


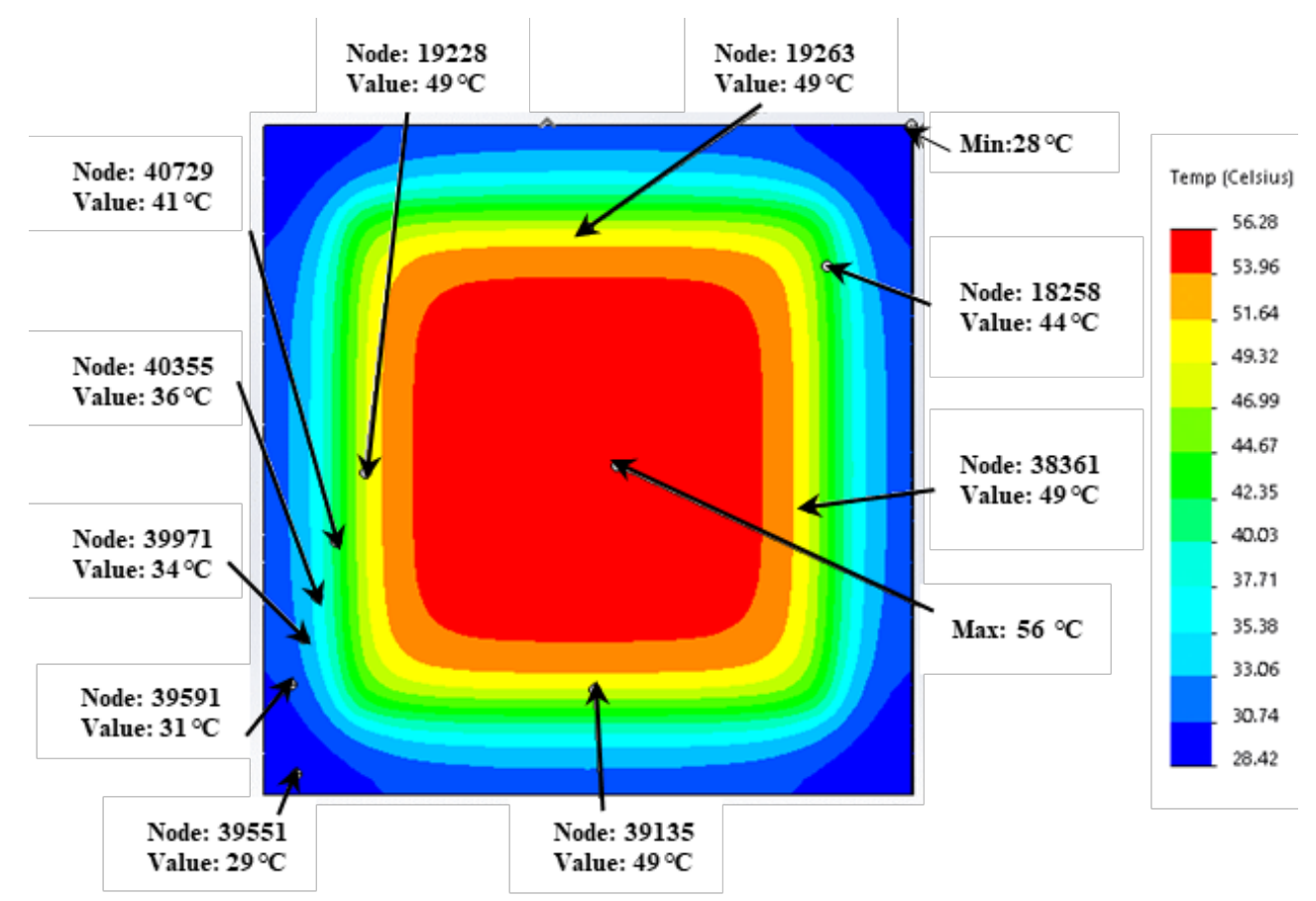

Fig. 6 Heat flux analysis results.

\section{Conclusion}

This study used finite element thermal conduction analysis to determine an effective method for heating ITO conductive heating films (i.e., heat power or heat flux). The results revealed that when using heat power to analyze ITO film thermal input, excessive thermal energy was input, resulting in an excessively high temperature and an unreasonable temperature distribution. By contrast, using heat flux as the thermal input source for ITO film resulted in relatively reasonable overall temperature distribution. Compared with experimental temperature measurements, the temperature distribution measurements of the current study were the same. On the basis of these results, an effective temperature compensation analysis method for ITO conductive heating film was established.

\section{References}

[1] Chuang, W. N., Tsao, W. C., and Hung, M. W. 2019. "Heating Temperature Distribution of ITO Film Heater." Journal of the Chinese Society of Mechanical Engineers. Paper No: \# 00600.

[2] Kim, H., Gilmore, C. M., Piqué, A., Horwitz, J. S.,
Mattoussi, H., Murata, H., Kafafi, Z. H., and Chrisey, D. B. 1999. "Electrical, Optical, and Structural Properties of Indium-Tin-Oxide Thin Films for Organic Light-Emitting Devices.” Journal of Applied Physics 86 (11): 6451-61.

[3] Cheng, L. S., Sun, B. S., Zhong, J. M., He, L. J., Wang, D. X., and Chen, H. M. 2008. "Research Progress of ITO Transparent Conductive Film.” Rare Metals Letters 3: $1-7$.

[4] Vossen, J. L. 1977. "Transparent Conducting Films.” Physics of Thin Film 9: 1-64.

[5] Exarhos, G. J., and Zhou, X. D. 2007. "Discovery-Based Design of Transparent Conducting Oxide Films.” Thin Solid Films 515: 7025-52.

[6] De, S., Higgins, T. M., Lyons, P. E., Doherty, E. M., Nirmalraj, P. N., Blau, W. J., and Coleman, J. N. 2009. "Silver Nanowire Networks as Flexible, Transparent, Conducting Films: Extremely High DC to Optical Conductivity Ratios.” ACS Nano 3: 1767-74.

[7] Rathmell, A. R., Bergin, S. M., Hua, Y. L., Li, Z. Y., and Wiley, B. J. 2010. "The Growth Mechanism of Copper Nanowires and Their Properties in Flexible, Transparent Conducting Films.” Advanced Materials 22: 3558-63.

[8] De, S., King, P. J., Lotya, M., O'Neill, A., Doherty, E. M., Hernandez, Y., Duesberg, G. S., and Coleman, J. N. 2010. "Flexible, Transparent, Conducting Films of Randomly Stacked Graphene from Surfactant-Stabilized, Oxide-Free Graphene Dispersions.” Small. 6: 458-64.

[9] Minami, T. 2000. "New n-Type Transparent Conducting Oxides.” MRS Bulletin 25: 38-44. 